\title{
TRANSTORNO DE DÉFICIT DE ATENÇÃO E HIPERATIVIDADE: o olhar da Gestalt Terapia
}

\author{
Luciane GUISSO ${ }^{1}$ \\ Ana Carla FABRO ${ }^{2}$ \\ ${ }^{1}$ Mestranda em Psicologia na Universidade Federal de Santa Catarina (UFSC), Psicóloga. \\ lucianeguisso@yahoo.com.br \\ ${ }^{2}$ Especialista em Gestalt Terapia pelo Comunidade Gestáltica (Florianópolis-SC), Psicóloga Clínica. \\ anacarlafabro@gmail.com
}

Recebido em: 08/05/2016 - Aprovado em: 22/08/2016 - Disponibilizado em: 18/12/2016

\section{RESUMO:}

O objetivo deste artigo é apresentar teoricamente como o Transtorno de Déficit de Atenção e Hiperatividade (TDAH) vem sendo compreendido na Psicologia, sob o viés da Gestalt Terapia, que concebe o homem como um ser inerentemente relacional e que se constrói a partir de seu existir com o mundo e com o outro. Destacase que, atualmente, o TDAH tem sido amplamente discutido, seja pela comunidade acadêmica, bem como pela sociedade de um modo geral. Uma vez que o número de "diagnósticos" tem aumentado em níveis alarmantes, diversos questionamentos têm sido realizados em torno do que realmente caracteriza este transtorno e suas formas de tratamento. Só um jeito de ser e/ou uma construção cultural e social? O TDAH tem mobilizado esforços e discussões em torno dos modelos tradicionais de tratamento, principalmente o medicamentoso. Assim, a psicoterapia tem se apresentado enquanto possibilidade de intervenção que auxilia no olhar mais abrangente em torno do diagnóstico, contemplando a expressão do sujeito enquanto ser único que reflete comportamentos aprendidos socialmente. A Gestalt Terapia tem sido uma possibilidade de trabalho com crianças e adolescentes diagnosticados com TDAH. Esta abordagem compreende o TDAH enquanto um aspecto apresentado pelo sujeito em sua totalidade. Na prática clínica, o terapeuta busca juntamente com o sujeito e a família conhecer as formas de contato interrompidas na sua vida, visando promover o seu desenvolvimento de potencialidades e awareness através do contato no campo.

Palavras-chave: Déficit de atenção; hiperatividade; transtorno; Gestalt terapia; Psicologia.

\section{ABSTRACT:}

The aim of this article is to theoretically present how the Attention Deficit Hyperactivity Disorder (ADHD) has been understood in Psychology under the bias of Gestalt Therapy, which conceives humans as being inherently relational and constructed from their existence with the world and with each other. It is highlighted that, currently, ADHD has been widely discussed, both by the academic community and by society in general. Since the number of "diagnostics" has increased at an alarming rate, several questions have been made around what really characterizes this disorder and its treatment forms. Just a way of being and/or a cultural and social construction? ADHD has mobilized efforts and discussions around traditional treatment models, mainly the one with medications. This way, psychotherapy has been presented as a possibility of intervention which helps in the wider look around the diagnosis, contemplating the expression of the subject as a unique being that reflects socially learned behaviors. Gestalt therapy has been a possibility of working with children and adolescents diagnosed with ADHD. This approach comprises ADHD as an aspect presented by the subject in its totality. In clinical practice, the therapist seeks, along with the subject and family, to know the contact forms interrupted in their lives, aiming to promote their potential and awareness development through contact in the field.

Keywords: Attencion deficit; hyperactivity; disorder; Gestalt therapy; Psycology. 


\section{Introdução}

O Transtorno de Déficit de Atenção e Hiperatividade (TDAH) tem sido bastante estudado e discutido pelos diversos segmentos da sociedade. Cada vez mais o debate em relação à perspectiva médicabiologicista, que historicamente tentou explicar o "dito transtorno", vem sendo ampliada. Temse buscado desmistificar os comportamentos próprios da idade em crianças e adolescentes, bem como os aqueles compreendidos como característicos do TDAH.

As estatísticas apontam para um aumento exacerbado de diagnósticos de TDAH nos últimos anos juntamente como a indicação medicamentosa. No Brasil, segundo os dados do Boletim de Farmacoepidemiologia da Agência Nacional de Vigilância Sanitária (ANVISA, 2013), o consumo do medicamento metilfenidato (Ritalina), utilizado no tratamento deste transtorno, aumentou $75 \%$ em crianças com idade de 6 a 16 anos, entre os anos de 2009 e 2011. Percebe-se, portanto, uma notória "banalização de tal transtorno", que se reflete nos índices cada vez maiores de diagnósticos, sobretudo, por negligenciarem o contexto relacional do estudante identificado com transtorno de atenção e/ou concentração.
Muitos autores, como Moysés \& Collares (2013), apontam que se vive em um momento da medicalização dos "supostos transtornos de aprendizagem". A medicalização corresponde à transformação de questões de ordem cultural, social, econômica em cunho individual. Assim, comportamentos como os descritos enquanto característico do TDAH são entendidos como características individuais do sujeito. Pouco se olha para o contexto ensino/aprendizagem enquanto mais um fator que pode contribuir para eminência dos comportamentos identificados e relacionados ao TDAH.

Deste modo, este artigo tem por objetivo apresentar teoricamente como o TDAH vem sendo compreendido na Psicologia, sob o viés da Gestalt Terapia. Esta abordagem tem como pressuposto epistemológico a perspectiva fenomenológica/existencial, que compreende o homem como um ser relacional que se constrói no contato com o meio, além de apresentar uma visão holística de doença.

\section{Contextualizando o TDAH}

Atualmente tem-se verificado um aumento considerável no número de diagnósticos relacionado os transtornos 
de aprendizagem na infância. Destacase que o TDAH, de forma geral, "caracteriza-se por distúrbios motores, perceptivos, cognitivos e comportamentais, expressando dificuldades globais do desenvolvimento infantil" (ANTONY; RIBEIRO, 2004, p. 127).

Nas diversas observações e estudos do TDAH, pais e professores comentam que as crianças "são capazes de se concentrarem horas em uma atividade que apreciam e em que são habilidosas (videogame, pintar, desmontar carrinhos) e que prestam atenção em tudo e em todos, mas são incapazes de se concentrar nas aulas e tarefas escolares" (ANTONY; RIBEIRO, 2005, p. 189).

A criança mostra interesse por situações ou objetos e "faz uso das funções da atenção (discriminar, selecionar, fixar) e confirma que o ato da atenção não é puramente cognitivo, mas depende de fatores motivacionais e afetivos subjacentes que interferem na escolha dos objetos" (ANTONY; RIBEIRO, 2005, p. 189).

A hiperatividade é uma característica marcante do TDAH, sendo que a criança expressa ampla movimentação corporal na realização de atividades ou mesmo quando está parada. Ela pode balançar pés e pernas excessivamente, mudando a posição corporal quando sentada. Percebe-se que "aparentemente, não tem domínio sobre seu corpo (é o corpo que a domina), e suas ações parecem involuntárias, manifestando um desencontro entre o sentir e o pensar" (ANTONY; RIBEIRO, 2005, p. 192).

Esse transtorno afeta cerca de 8 a $12 \%$ das crianças no mundo. Os dados do "Centro de Controle e Prevenção de Doenças (CDC) dos Estados Unidos, de 2007, indicam que aproximadamente 9,5\% (5,4 milhões) de crianças e adolescentes americanos de 4 a 17 anos tinham TDAH” (BRASIL, 2012, p. 01). No Brasil, estudos apontam que o transtorno atinge de $3 \%$ a $5 \%$ da população. É mais comum em meninos (9\%) com sintomas de hiperatividade do que em meninas (3\%), que apresentam mais sintomas de desatenção (ROHDE et al., 2000).

Em muitos casos, o TDAH vem sendo tratado medicamentosamente, com o metilfenidato. A justificativa é que, “esse medicamento, sujeito a prescrição médica, promove um 
aumento da atenção e do controle de impulsos de crianças que apresentam TDAH” (BRASIL, 2012, p. 01). Embora não existam estudos conclusivos sobre a etiologia orgânica do TDAH, há a presença de controvérsias sobre o uso da medicação. Tem-se questionado a "crença (...) que apregoa que várias formas de sofrimento, de mal-estar, de transtornos psíquicos têm causas orgânico/genéticas, devendo ser tratadas e curadas pelas práticas médico/psiquiátricas medicamentosas (LEGNANI; ALMEIDA, 2009, p. 16).

Nos estudos que procuram encontrar uma causa biológica específica para o TDAH, fica claro que "evidências conclusivas de lesão ou disfunção neurofisiológica são pouco substanciais e continuam incertas" (ANTONY; RIBEIRO, 2005, p. 127). Dessa forma, explicações simplistas e explicações unicausais são fadadas ao fracasso, uma vez que o distúrbio tem sido visto de forma cada vez mais complexa e multidimensional.

Salienta-se que é fundamental compreender o contexto da criança, pois muitas vezes os sintomas são reflexos de uma situação familiar conflitiva ou mesmo decorre de práticas de ensino que não contemplam o olhar para a singularidade presente no contexto da sala de aula. Conforme Antony e Ribeiro (2008, p. 218), “o problema reside no fato que omite ou dá insuficiente atenção às questões social, política, econômica, psicológica e educacional que circundam este termo desde o seu início”.

\section{A Gestalt Terapia e a visão de}

\section{homem}

No viés gestáltico, o homem é visto como um ser de infinitas potencialidades para crescer e se desenvolver, estando diariamente em construção e, portanto, inacabado. É sempre "algo que pode vir a ser outra coisa num momento seguinte; o homem é um constante vir a ser, é um ser em processo" (AGUIAR, 2005, p. 44). Também é visto enquanto unidade indivisível e um ser inerentemente relacional, que se constrói e se reconstrói a cada instante a partir de seu existir com o mundo e com o outro, o que estabelece um campo organismo/ambiente (ALVIM; BOMBEN; CARVALHO, 2010). 
Esse campo "constitui uma unidade indissociável, uma totalidade cujo significado emerge das interrelações entre as partes que compõem um dado todo. Tudo está interligado, tudo depende de um outro todo" (ANTONY; RIBEIRO, 2008, p. 22). Assim, qualquer ação da pessoa no campo não vem separada do contexto e todas as suas vivências e experiências se organizam em uma teia de relacionamentos que se interpenetram, o que difere da noção de causa e efeito. Compreende-se que a pessoa existe a partir das relações estabelecidas com seu mundo e com os outros. A integração da pessoa e do mundo se dá por meio dos processos de ajustamento criativo. Esses resultam ou são uma capacidade do homem de satisfazer as suas necessidades conforme as possibilidades no campo organismo/ambiente.

Dois conceitos são fundamentais dentro desta abordagem: contato e awareness. Contato corresponde a experiência na fronteira entre o "eu" e o "não-eu"; é algo dinâmico, seletivo e criativo. Verifica-se que todo contato é ajustamento criativo do organismo e ambiente (PERLS; HEFFERLINE;
GOODMAN, 1951). Para esses autores, "o contato é awareness da novidade assimilável e comportamento com relação a esta; e rejeição da novidade inassimilável. O que é difuso, sempre o mesmo, ou indiferente, não é um objeto de contato" (PERLS; HEFFERLINE; GOODEMAN, 1951, p. 44). Já a awareness é a "tomada de consciência global no momento presente, atenção ao conjunto de percepção pessoal, corporal e emocional, interior e ambiental, consciência de si e consciência perceptiva" (GINGER; GINGER, 1995, p. 254). Correspondem ao processo de dar-se conta do que faz e como se sente no momento presente.

Quando as funções de contato são fluídas no campo, a pessoa irá realizar contatos mais plenos com o ambiente, de forma a suprir as suas próprias demandas. É um fluxo livre de formação e fechamento de figuras, que ocorre em um processo de contato e awareness, o que leva a autorregulação organísmica. Mas se as funções de contato estiverem "bloqueadas ou distorcidas, certamente o contato (...) com o mundo, com o outro e consigo mesmo se apresentará diminuído" (AGUIAR, 2005, p. 109). Neste caso, 
ocorrem as interrupções de contato e a pessoa se torna incapaz de alterar suas técnicas de manipulação e interação com o meio (PERLS, 1988), ocasionando gestalten "abertas e necessidades não satisfeitas, o que gera desequilíbrio no funcionamento natural do organismo" (ANTONY; RIBEIRO, 2008, p. 222). Para Frazão (1997, p. 68), “a 'awareness' será empobrecida, levando a formas de contato disfuncionais".

A exposição constante da pessoa a situações de angústia e tensão provocam bloqueios em seu contato com o meio. Esses bloqueios "são mecanismos psicológicos com funções defensivas que visam inibir a consciência de sentimentos, pensamentos, comportamentos que geram ansiedade e colocam em risco a relação com o outro significativo" (ANTONY; RIBEIRO, 2008, p. 222). Compreende-se que as interrupções de contato são também formas pelas quais as pessoas garantem a sua sobrevivência. Por outro lado, sabe-se que as situações inacabadas que permanecem dificultam a realização de contatos saudáveis. A seguir serão abordadas, resumidamente, as formas mais presentes de interrupção de contato nas crianças, bem como nos adolescentes e adultos. São elas: introjeção, confluência, retroflexão, deflexão e projeção.

$\mathrm{Na}$ introjeção o mundo é incorporado pela criança por meio da assimilação, o que representa a forma saudável de introjetar. Esse movimento é fundamental para a construção das fronteiras de contato iniciais da criança, uma vez que esta necessita desta referência para organizar-se. Quando as necessidades do outro são vistas como únicas certezas, ocorre a inversão dos afetos: a criança experimenta a substituição do seu excitamento genuíno (sua necessidade) pela figura do outro. A criança percebe que "dizer não ao mundo significa desagradar às pessoas em alguns momentos, quebrar, regras e não ser totalmente querida em outros momentos" (AGUIAR, 2005, p. 111).

$\mathrm{Na}$ confluência, a criança entende-se como extensão da sua mãe. Nesse tipo de relacionamento há ausência de fronteira de contato, sendo que a criança não tem um espaço para demonstrar suas reais necessidades (AGUIAR, 2005). Neste caso, está 
disfuncional e não se reconhece, afastando-se de si mesma.

Referente à retroflexão, a criança acaba retornando para si própria a energia que gostaria de ter aplicado no outro ou que o outro lhe aplicasse. Essas crianças, geralmente, apresentam doenças que não possuem "retorno médico eficaz", pois "na ausência de palavras e de formas permitidas de se expressarem no mundo, elas voltam para o seu corpo aquilo que percebem como não tendo saída" (AGUIAR, 2005, p. 113).

Outra interrupção de contato é a deflexão. A criança parece não "dar importância ou reconhecimento" ao que está ocorrendo. Ela emite comportamentos de "fazer de conta" que não é com ela que a palavra ou ação está sendo dirigida, ou muda de assunto ou então afirma não saber. Para Antony (2006), a criança deflete por não tolerar ataques ao seu eu e por não conseguir lidar com as tensões do mundo adulto.

E por fim, na projeção a criança aponta no outro particularidades de sua personalidade que muitas vezes não consegue aceitar em si própria. Ou seja, "elas nos falam de seus sintomas apontando-os em outras crianças: a menina que diz que a irmã mais nova faz pipi na cama, ou o menino que diz que o coleguinha da escola é muito bagunceiro" (AGUIAR, 2005, p. 113). Por temer a punição e a crítica, não assume a responsabilidade de suas ações (ANTONY, 2006).

Para a Gestalt Terapia, pensar em "saúde" é falar de autorregulação organísmica. "Contato é saúde. Saúde é contato em ação. Qualquer interrupção do contato implica uma perda na saúde" (RIBEIRO, 1997, p. 53). Deste modo, os comportamentos repetitivos e estereotipados levam a criança ao processo de adoecimento. Para Antony e Ribeiro (2004, p. 193), a “doença significa bloqueios do contato originados por mecanismos psicológicos com funções defensivas que visam inibir a consciência de sentimentos, pensamentos, comportamentos que geram ansiedade e colocam em risco a relação com o outro significativo". No olhar gestáltico, portanto, adoecer é um processo que resulta de uma não harmonia relacional entre organismo e ambiente. A “doença é relacional. Não existe doença em si. Doença é fenômeno como processo; como dado, existe em alguém, e não 
como realidade em si mesma" (RIBEIRO, 1997, p. 36).

\section{Gestalt Terapia e TDAH}

As mudanças que vêm ocorrendo ao longo dos anos em nossa sociedade refletem nos processos de atenção e hiperatividade. Certamente o contexto em que as crianças da década de 60 estavam inseridas é diferente das crianças de hoje. Cada vez mais as crianças atuais têm suas agendas completas de atividades extraclasses, permanecendo a maior parte do seu tempo em ambientes fechados e protegidos, restando quase nada de tempo para as brincadeiras ao ar livre. A sociedade tem demandado uma atenção focalizada em um mundo que predomina a atenção dispersa e flutuante. Assim, pode-se refletir sobre o TDAH a partir da análise do campo, sua evolução histórica e o processo de desenvolvimento de cada criança através de suas experiências de contato.

Na Gestalt Terapia, o TDAH é compreendido como um problema de limite de contato, ou seja, o indivíduo tem dificuldades de manter contato saudável com alguém ou algo (OAKLANDER, 2008).
Estudos no enfoque da Gestalt Terapia com crianças identificadas com TDAH apontam que elas "respondem ao mundo com hiperatividade, hiperatenção e hiperemotividade, como uma totalidade em ação. (...) estas crianças e jovens não aceitam os modelos rígidos e métodos padronizados de ensino impostos pelas escolas e famílias" (ANTONY; RIBEIRO, 2008, p. 25).

Dessa forma, a instabilidade motora aparece como figura psicomotora de um fundo desorganizado em que a hiperatividade mostra-se como um sintoma em sua aparência, e, como todo o sintoma, representa uma forma de defesa (AJURIAGUERRA; MARCELLI, 1986). O fundo desorganizado representa uma forma encontrada pela criança "hiper" de apropriar-se do mundo, de seu corpo e estabelecer contato.

Podem-se compreender os sintomas do TDAH a partir do mecanismo de autorregulação, isto é, como uma tentativa da criança de interagir com o mundo e lidar com as demandas do meio nos dias de hoje. Segundo Lázaro (2015, p. 24), nessas 
tentativas o que a criança "consegue manifestar é sua falta de controle através do corpo, indicando uma desarmonia entre o sentir, o pensar e o agir". Essa autora traz em seu estudo a compreensão de que o TDAH está no campo, no ritmo acelerado da sociedade moderna, sendo que as crianças que apresentam seus sintomas estão procuram se autorregular.

Muitas vezes, as crianças diagnosticadas com TDAH travam "uma luta interna na qual tem de renunciar ao seu modo de ser, aos seus movimentos, ao seu espaço, às suas necessidades, em troca de satisfazer as vontades e expectativas alheias, por não poder ser aquilo que é" (ANTONY; RIBEIRO, 2008, p. 221).

$O$ excesso de excitação na criança mobiliza-a constantemente para a ação, muitas vezes de forma impulsiva. Com isso, "mantém um contato superficial com as coisas, trocando incessantemente $\mathrm{o}$ foco da atenção ou ação de um objeto a outro prematuramente, sem manter a continuidade até o fechamento da gestalt" (ANTONY; RIBEIRO 2004, p. 195). Como não se satisfaz amplamente, a criança tem dificuldade em adquirir uma harmonia organística, manifestando-se insatisfeita. Ela vive "um processo interminável de busca da própria auto-regulação, onde a hiperatividade e a desatenção disfarçam a condição essencial da síndrome que reflete uma busca alienada de objetivos e de sentido para a existência" (ANTONY; RIBEIRO, 2004, p.195). No olhar de Oaklander (2008, p.197), os sintomas do TDAH podem ser vistos como "deflexiones, defesas e evitaciones de emociones".

É importante ressaltar que as crianças com TDAH possuem dificuldades de seguir regras e limites. Dessa forma, compreende-se a necessidade da construção conjuntamente com as mesmas de um trabalho envolvendo pensar rotinas e limites mais claros, conforme cada idade. "Los niños se angustian em um ambiente donde no hay estructura ni limites bien definidos, y al tratar de librarse de este sentimiento, tienden a manifestar sus conductas" (OAKLANDER, 2008, p. 198). Ademais, crianças precisam ser auxiliadas a reconhecer seus próprios sentidos, como: "mirar, escuchar, tocar, oler, saborear, moverse, hacer 
afirmaciones, expresar emociones, son todas funciones de contacto" (OAKLANDER, 2008, p.205), cujo objetivo está em fortalecer e integrar na criança o sentido de si mesmo. Lázaro (2015) afirma que quando a criança tem um bom sentido do eu, ela aceita o poder e o controle de seus pais, por outro lado é essencial que ela tenha experiências de controle e poder, dentro das limitações cabíveis, o que proporciona à criança a sensação de domínio e não de disputa de poder com seus pais.

Quando as funções de contato interrompidas são atualizadas, a própria criança se reorganiza e reestrutura sua forma de relação consigo e com o meio. A criança com TDAH que não está aware em relação ao seu corpo e sentimentos necessita que pais, professores e profissionais da saúde envolvidos desenvolvam estratégias de intervenção que possibilite a mesma novas experiências de contatos, visando sempre o processo e não o conteúdo. É focar na experiência da criança de se envolver com os sentidos e o corpo, proporcionando a ela novas formas de contato com a sua realidade. Deve-se olhar para o que apresenta-se como saudável na criança para favorecer o desenvolvimento de suas potencialidades e awareness através de seu contato no campo.

Acredita-se, dentro da perspectiva da Gestalt Terapia, que a construção de novas formas de contato permite a criança de "assumir responsabilidade por suas escolhas e ações, ser capaz de criar metas e objetivos para dar sentido a sua vida, saber hierarquizar suas necessidades para poder ajustar-se criativamente ao meio" (ANTONY; RIBEIRO, 2004, p. 196).

\section{Considerações finais}

O TDAH corresponde a um transtorno que tem passado por diversas definições ao longo dos anos. Sua origem e causa são controversas entre as diferentes áreas científicas. Nas crianças, o TDAH tende a ser percebido geralmente quando esta vai para a escola. Os educadores, na maioria dos casos, são os agentes que chamam as famílias e encaminham o estudante para o tratamento esperado.

Ressalta-se que as críticas em relação à exacerbação de diagnósticos e indicação medicamentosa têm sido 
discutidas por vários setores da sociedade. Para a Gestalt Terapia, o TDAH tem sido pensado enquanto uma forma de contato do sujeito com o ambiente. Esta abordagem fenomenológica/existencial compreende que os sintomas são tentativas de adaptação da criança ao seu meio. $\mathrm{O}$ terapeuta gestáltico busca juntamente com a criança desenvolver outras formas de autorregulação que supram as necessidades dela no meio.

De um modo geral, espera-se que os profissionais da saúde e da educação compreendam a ocorrência dos fenômenos em sua totalidade, ou seja, levando em conta os contextos sociais, as novas tecnologias, os novos arranjos das relações, que estão atrelados à subjetividade de cada criança antes de quaisquer diagnósticos. Significa discernir cada situação e avaliar quais as estratégias de intervenção são necessárias.

Por fim, ressalta-se que o tema deste trabalho não se esgota aqui, merecendo ampla discussão da sociedade em relação às formas como vem sendo percebido e entendido, sobretudo no que concerne estabelecer um diagnóstico. Por detrás deste, existe uma pessoa com infinitas potencialidades e que precisa ser entendida e aceita em sua forma singular de ser e estar no mundo.

\section{Referências}

AGUIAR, L. Gestalt terapia com crianças: teoria e prática. São Paulo: Livro Pleno, 2005.

AJURIAGUERRA, J.; MARCELLI, D. Manual de psicopatologia infantil. Porto Alegre: Artes Médicas, 1986.

ALVIM, M. B.; BOMBEN, E.;

CARVALHO, N. "Pode deixar que eu resolvo!" - retroflexão e contemporaneidade. Revista da Abordagem Gestáltica, v.16, n.2, p.183-188, 2010.

ANTONY, S. A criança em desenvolvimento no mundo: um olhar gestáltico. IGT na Rede, v.3, n.4, 2006.

ANTONY, S.; RIBEIRO, J. P. Criança hiperativa: uma visão da gestalterapia. Revista Psicologia - teoria e pesquisa. v.20, n.2, p.127-134, 2004.

Hiperatividade: doença ou essência - um enfoque da gestaltterapia. Psicol. Cienc. Prof., v.25, n.2, p. 186-197, 2005. Compreendendo a hiperatividade: uma visão da GestaltTerapia. Revista Ciências Saúde, v.19, n.3, p.215-224, 2008.

ANVISA. Agência Nacional de Vigilância Sanitária. Estudo aponta crescimento no consumo do metilfenidato. 2013. Disponível em 
<http://portal.anvisa.gov.br/wps/content /anvisa+portal/anvisa/sala+de+imprensa /assunto+de+interesse/noticias/estudo+a ponta++tendencia+de+crescimento+no+ consumo+de+metilfenidato $>$. Acesso em: 28 mar. 2016.

BRASIL. Prescrição e consumo de metilfenidato no Brasil: identificando riscos para o monitoramento e controle sanitário. SNGPC - Boletim de farmacoepidemiologia, n.2, 2012. Disponível em: < http://www.anvisa.gov.br/sngpc/boletin s/2012/boletim_sngpc_2_2012_corrigid o_2.pdf >. Acesso em: 20 mar. 2016.

FRAZÃO, L. M. Funcionamento saudável e não saudável enquanto fenômenos interativos. Revista do III Encontro Goiano da Abordagem Gestáltica, p. 64-71, 1997.

GINGER, S.; GINGER, A. Gestalt: uma terapia de contato. São Paulo: Summus, 1995.

\section{LÁZARO, J. M. O TDAH na luz da}

Gestalt: um diagnóstico de campo. 36 f. Monografia (Especialização) - Curso de Especialização em Gestalt Terapia, Comunidade Gestáltica, Florianópolis, 2015.

LEGNANI, V. N.; ALMEIDA, S. F. C. Hiperatividade: o não-decidido da estrutura ou o infantil ainda no tempo da infância. Revista Dossie, 2009.

MOYSÉS, M. A. A.; COLLARES, C. A. L. Controle e medicalização da infância. Revista Desigualdades, v.1, n.1, 2013.

OAKLANDER, V. El Tesoro escondido. Chile: Cuatro Vientos, 2008.
PERLS, F. A abordagem gestáltica e testemunha ocular da terapia. 2 ed. Rio de Janeiro: Guanabara Koogan, 1988.

PERLS, F.; HEFFERLINE, R.;

GOODMAN, P. Gestalt-Terapia. São Paulo: Summus, 1951.

RIBEIRO, J. P. O Ciclo do Contato. São Paulo: Summus, 1997.

ROHDE, L. A., et al. Transtorno de déficit de atenção/hiperatividade.

Revista Brasileira de Psiquiatria, v. 2, n.2, 2000 . 